\title{
Exploring the Effects of Exercise on Brown Adipose Tissue Volumes and T2 Values Using Magnetic Resonance Imaging at 7 Tesla
}

\section{Yan Zeng}

Third Hospital of Hebei Medical University https://orcid.org/0000-0002-8578-5008

\section{Lei Gao}

Third Hospital of Hebei Medical University

\section{Shuying Shao}

Third Hospital of Hebei Medical University

\section{Xiaoshuai Chen}

Third Hospital of Hebei Medical University

\section{Ping Zhang}

Third Hospital of Hebei Medical University

\section{Ranxu Zhang}

Third Hospital of Hebei Medical University

\section{Xiaoyue Zhou}

Simens Healthineers Ltd.Shanghai

Jian Zhao ( $\sim$ zhaojiansohu@126.com )

Third Hospital of Hebei Medical University

\section{Research Article}

Keywords: BAT, exercise, MRI, T2 mapping, running

Posted Date: March 9th, 2021

DOI: https://doi.org/10.21203/rs.3.rs-191473/v1

License: (1) (1) This work is licensed under a Creative Commons Attribution 4.0 International License. Read Full License 


\section{Abstract \\ Rationale and Objectives:}

We aimed to evaluate the effect of exercise on brown adipose tissue (BAT) volumes and T2 values in mice.

\section{Materials and Methods}

Twenty-five female Kunming mice were divided into two groups, a running group $(n=5)$ and a control group $(n=20)$. After 4 months, all magnetic resonance imaging (MRI) scans of mice were performed on a 7 Tesla (7T) MR scanner with T2-weighted imaging (T2WI) and a T2 mapping sequence. Interscapular brown adipose tissue (BAT) volumes and T2 values were measured. To reduce the impact of weight on the results, we compared the ratio of BAT volumes to body weights $(\mathrm{V} / \mathrm{W})$. The data are expressed as mean $\pm S D$, the BAT $V / W$ and $T 2$ values were compared between the control and running groups using the Wilcoxon rank-sum test, $\mathrm{P}<0.05$ were considered statistically significant.

\section{Results}

Interscapular BAT volumes of the running group $(n=5)$ and control group $(n=20)$ were $(180.09 \mathrm{ml} \pm 59.80$ $\mathrm{ml}$ ) and $(99.98 \mathrm{ml} \pm 35.05 \mathrm{ml})$, respectively. The $V / W$ ratios of the running and control groups were $(3.83 \mathrm{ml} / \mathrm{g} \pm 0.78 \mathrm{ml} / \mathrm{g})$ and $(2.17 \mathrm{ml} / \mathrm{g} \pm 0.56 \mathrm{ml} / \mathrm{g})$, respectively. Interscapular BAT T2 values of the running and control groups were $(76.07 \mathrm{~ms} \pm 10.82 \mathrm{~ms})$ and $(61.22 \mathrm{~ms} \pm 15.98 \mathrm{~ms})$, respectively. Significant differences were found in the BAT V/W ratios $(P=0.0003, P<0.001)$ and $T 2$ values between the two groups $(P=0.0096, P<0.05)$. BAT volume correlated positively with BAT T2 value $(r=0.75, p=0.00002)$.

\section{Conclusions}

MRI is a non-invasive and quantitative method for identifying BAT, especially at ultra-high field like 7T. Long-term running increases BAT volume and T2 value, what's more, BAT volume correlates positively with BAT T2 value.

\section{Introduction}

Two main types of adipose tissues exist in mammals, brown adipose tissue (BAT) and white adipose tissue (WAT). Although they are both adipose tissues, they have different compositions. BAT cells have many small lipid droplets and mitochondria, while WAT cells contain a single large lipid droplet and fewer mitochondria. In the body, the amount of WAT is much larger than BAT. BAT has been verified to play an important role in energy expenditure and the maintenance of metabolic balance [1]. For human being, it 
infants and gradually decreased with age [2]. In recent years, with the development of 18F-

fluorodeoxyglucose positron emission tomography/computed tomography ( ${ }^{18} \mathrm{~F}$-FDG PET-CT), researchers have found active BAT in adults $[3,4]$. This BAT consumed glucose and fatty acids participate in nonshivering thermogenesis to generate heat, and the investigators suggested a possible role for BAT in protecting against obesity. Since then, additional studies have found that BAT improved the metabolism of obese, diabetic and dyslipidemic patients $[5,6]$. Therefore, clarifying BAT mechanisms is of great importance in the treatment of these diseases. At present, assessing BAT activity is mainly based on ${ }^{18} \mathrm{~F}$ FDG PET-CT, histology, or serologic examination. PET-CT is the main imaging method for BAT evaluation; however, ionizing radiation limits its application, and it can only detect activated BAT. There is an urgent need for noninvasive and relatively convenient evaluation methods. Chen et al. [7] showed that BAT could be distinguished from other tissues on MRI because fat-water content and mitochondrial densities are different between WAT and BAT [1]. At present, there are many kinds of methods for BAT research, such as proton density fat fraction (PDFF) and T2* mapping, however, these methods are complicated and need expensive device that limit their application. On the contrary, T2 mapping were widely used in the clinical routine, such as heart, cartilage evaluation and so on[8,9], so we think it may be a good candidate for BAT research [10].

Currently, research regarding the factors that influence BAT primarily focus on cold exposure and exercise. Most studies show that cold exposure promotes BAT formation [11-13]. When the body is stimulated by cold temperatures, BAT plays an important role in non-shivering thermogenesis to ensure body temperature stability. As we all know, exercise can accelerate glucose and fatty acid consumption, reduce weight, reduce WAT amounts, and improve metabolic conditions. However, no matter in mice or human, the relationship between exercise and BAT remains unclear. Studies looking at the effects of exercise on BAT have shown conflicting results[14-19]. Therefore, in this study, T2WI and T2 mapping sequences were used to evaluate BAT volumes and T2 values, respectively, and the relationship between exercise and BAT was explored.

\section{Materials And Methods}

\section{Animals, the exercise program, and the morphometric analyses}

Twenty-five female Kunming mice weighing about $20 \mathrm{~g}$ (aged 5-6weeks) were included in the study. The mice were divided into two groups according to their exercise habits (each mouse was subjected to treadmill activities, and we observed a willingness to run, the observation lasted for three days, the mice those ran for more than 1 hour every day in the selection period were considered to have the willingness to run). Those that were willing to run were assigned to the running group $(n=5)$, and those who did not were assigned to the control group $(n=20)$. The mice were kept in a room with a constant temperature of $22^{\circ} \mathrm{C}$, with a $12 / 12 \mathrm{~h}$ light-dark cycle and sufficient food and water. Mice in the running group performed

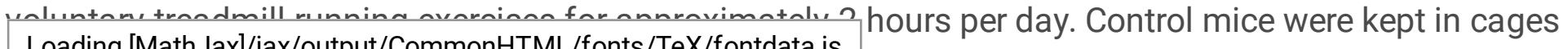
Loading [MathJax]/jax/output/CommonHTML/fonts/TeX/fontdata.js 
and were not subjected to running on a treadmill. After 4 months, MR scanning of all the mice was performed. Since the interscapular area has the largest amount of BAT in rodents [20], we focused on this area for evaluations.

After scanning, the mice were sacrificed. Interscapular BAT was immediately dissected out and stored at $-80^{\circ} \mathrm{C}$ for later processing. BAT tissue sections were obtained and stained with hematoxylin \& eosin for morphologic assessments and morphometric analyses.

\section{The imaging protocol and measurements}

All the mice were scanned on a 7 Tesla (7T) MR scanner (BioSpec 70/30 USR, Bruker BioSpin MRI GmbH, Ettlingen, Germany) with a mini imaging gradient coil system. All animals were examined using T2WI and T2 mapping sequences. A T2WI sequence adopted rapid acquisitions with relaxation enhancements (RAREs) with the following parameters: repetition time $(T R)=2400 \mathrm{~ms}$, echo time $(T E)=24 \mathrm{~ms}$, average $=$ 5 , matrix size $=256 \times 256$, field of view $(F O V)=25 \times 30 \mathrm{~mm}$, slice thickness $=0.7 \mathrm{~mm}$, number of slices $=20$, and no fat suppression. Mimics software (Materialise N.V. Version 16.0.0.220) was used to measure BAT volumes using the T2WI sequence (Fig. 1). BAT boundaries were manually outlined by two radiologists (ICC = 0.941), and the volumes were calculated using the software. The low signals in BAT are blood vessels, which were not included in our measurements, and then the average measured values were taken. T2 mapping imaging can obtain T2 values with multiple slices multiple echo (MSME) using the following parameters: repetition time $(T R)=4200 \mathrm{~ms}$, a twenty-five echo time $(T E)=8-200 \mathrm{~ms}$ with an interval $\triangle T E=8 \mathrm{~ms}$, matrix size $=256 \times 256$, field of view $(F O V)=25 \times 30 \mathrm{~mm}$, and flip angle $=90^{\circ}$, slice thickness $=0.7 \mathrm{~mm}$, number of slices $=20$. The $\mathrm{T} 2$ values were measured by two radiologists, using Viewing software (BioSpec 70/30 USR, Bruker BioSpin MRI GmbH, Ettlingen, Germany).

\section{Statistical analyses}

BAT volumes could be affected by body weight, and therefore, to reduce the impact of weight on the results, we compared the ratios of BAT volumes to body weights $(\mathrm{V} / \mathrm{W})$ between the control and running groups. The data are expressed as mean \pm SD, statistical analysis was performed by SPSS (version 21.0), the BAT V/W ratios and T2 values between the control and running groups were compared using the Wilcoxon rank-sum test. P-values $<0.05$ were considered statistically significant. Spearman's correlation was performed to analyze the correlation between BAT volumes and BAT T2 values.

\section{Results}

We can see that interscapular brown adipose tissue (BAT) could be distinguished from surrounding tissue on T2 image (Fig. 1) and on T2 mapping artificial color image (Fig. 2).

The interscapular BAT stained with a hematoxylin and eosin stain. Brown adipocytes with multiple small cytoplasmic lipid droplets were shown in Fig. 3. 
Interscapular BAT volumes in the running group $(n=5)$ and the control group $(n=20)$ were $(180.09 \mathrm{ml} \pm$ $59.80 \mathrm{ml})$ and $(99.98 \mathrm{ml} \pm 35.05 \mathrm{ml})$, respectively. The $\mathrm{V} / \mathrm{W}$ ratios of the running and control groups were $(3.83 \mathrm{ml} / \mathrm{g} \pm 0.78 \mathrm{ml} / \mathrm{g})$ and $(2.17 \mathrm{ml} / \mathrm{g} \pm 0.56 \mathrm{ml} / \mathrm{g})$, showing a statistical difference between the groups $(P=0.0003, P<0.001)$. Interscapular BAT T2 values of the running and control groups were $(76.07 \mathrm{~ms} \pm$ $10.82 \mathrm{~ms})$ and $(61.22 \mathrm{~ms} \pm 15.98 \mathrm{~ms})$, respectively, showing a statistical difference between the groups $(P=0.0096, P<0.05)$ (Fig. 4).

BAT volume correlated positively with BAT T2 value $(r=0.75, p=0.00002)$.

\section{Discussion}

At present, the main method to evaluate BAT is with ${ }^{18} \mathrm{~F}-\mathrm{FDG}$ PET-CT, however, this method uses ionizing radiation, limiting its application. ${ }^{18}$ F-FDG PET-CT detects glucose tissue uptake, which could be affected by external factors, such as serum glucose levels, diets, and environmental temperatures. All of these factors could cause BAT concentrations to be underestimated [21]. Recently, MRI begins to be used in BAT research studies as a nonradioactive imaging method. Since BAT has been shown to have different fractions of fatty acids and water content compared with those of WAT, BAT and WAT tissues can be distinguished by MRI[10].

Although many studies have been published on the relationship between exercise and BAT, this relationship is still controversial. In our study, interscapular BAT V/W ratios were higher in the running group than that in the control group, which demonstrated that running exercise promoted BAT proliferation. The result of our study was similar to those of several previous studies $[19,17,14,16]$, whose subjects included rats and mice, and the exercises included swimming and running.

At present, the relatively accepted pathway of BAT activation during exercise is that the SNS is stimulated. The result is that target proteins, such as hormone-sensitive lipase, triglyceride lipase, and monoacylglycerol lipase, are phosphorylated, promoting the degradation of triglycerides in adipocytes and releasing free fatty acids to activate UCP1, resulting in increased thermogenesis [22-24]. Peres Valgas da Silva et al. showed that mature brown adipocytes from exercise-trained BAT had reduced glucose uptake in the absence of innervation, demonstrating that neural innervation is greatly significant for BAT functions [25].

However, some studies have shown that exercise decreases BAT activity $[18,15]$. In one study, male rats, subjected to moderately intense treadmill running to replicate endurance exercise, had decreased thermogenic capacities in classic BAT. In this study, the BAT of the trained rats had decreased UCP1 expression and a reduction in fatty acids, indicating that exercise decreased BAT activity. From a physiologic perspective, the authors surmised that increased BAT activity during exercise did not seem reasonable. In this theory, since BAT is a thermogenic tissue, its activation during exercise might seem like a waste of energy since exercise consumes energy and produces heat. To keep the body temperature stable. BAT activitv would need to be inhibited.

Loading [MathJax]/jax/output/CommonHTML/fonts/TeX/fontdata.js

Page 5/13 
In human studies looking at the impact of exercise on BAT also showed conflicting results. One study evaluated BAT activity in endurance-trained athletes by using ${ }^{18} \mathrm{~F}-\mathrm{FDG}$ PET-CT. Compared to the control group, endurance-trained athletes showed lower cold-induced BAT [26]. However, in another ${ }^{18} \mathrm{~F}$-FDG PETCT study of 40 cancer patients, increased habitual physical exercise (light exercise) led to higher BAT activity [2].

We speculate that there could be several reasons for the conflicting results. First, different exercises, such as swimming and running, could have varying results. For instance, swimming, as opposed to running, could result in a loss of heat due to the body's contact with water, thereby activating the thermogenic function of BAT. Second, there could be a difference in the duration and intensity of exercise. In previous studies, both short-term exercise and long-term endurance training have been evaluated. Whether these exercises can activate BAT compensatory mechanisms remains unclear. Third, different assessment methods could lead to different results. ${ }^{18} \mathrm{~F}$-FDG PET-CT is one method that is affected by several variables, including ambient temperatures, blood glucose levels, and diet. If these variables are not well controlled, BAT quantities would be likely underestimated. Free fatty acids (FFA) have also been shown to be the main substrate for BAT thermogenesis [20], and, therefore, it is doubtful if ${ }^{18} \mathrm{~F}$-FDG PET-CT can truly reflect BAT metabolism. Moreover, the evaluation of BAT volumes using MRI is still in the exploratory stages, more studies and samples are required to standardize the evaluation methods.

In our study, we found that the mice in running group had higher interscapular BAT T2 values than those in the control group. We speculated that the increased T2 values in our study were mainly due to the increased BAT volume. That is to say, the interstitial components increased as the volume of BAT increased, leading to more water content in tissue. Secondly, due to long-term exercise stimulating BAT through the SNS, and with BAT oxygen supplies fully compensated, more oxyhemoglobin would be available in this region, results in an increase of the T2 values. Our study showed that BAT volume correlated positively with BAT T2 value. The change of T2 value may reflect the change of BAT volume to a certain extent, as the distribution of BAT in human is relatively scattered, making it difficult to measure[27].

There are some limitations to our study. First, there was a disparity in the number of mice in the running group compared with the number in the control group, which was primarily caused by a lack of preparation in the early selection of mice, with an excessive number of mice that refused to exercise. Second, our study is considered preliminary, lacking protein and gene expression analyses, which will be performed in future studies.

\section{Conclusions}

In summary, this study was a non-invasive and quantitative examination method using 7T MRI to identify BAT. Long-term running increases BAT volume and T2 value, what's more, BAT volume correlates positively with BAT T2 value. 


\section{Abbreviations}

BAT: brown adipose tissue;

WAT: white adipose tissue;

V/W: ratio of BAT volumes to body weights;

UCP1: uncoupling protein 1;

SNS: sympathetic nervous system;

$\beta$-AR: $\beta$-adrenergic receptor;

cAMP: cyclic adenosine monophosphate;

PKA: cAMP-dependent protein kinase A;

p38MAPK: mitogen-activated protein kinase p38;

CREB: cAMP response element-binding protein;

IL-6: interleukin-6;

BAIBA: $\beta$-aminoisobutyric acid;

FGF21: fibroblast growth factor 21;

FFs: fat fractions;

NE: norepinephrine;

\section{Declarations}

\section{Acknowledgments}

We thank the Pathology Laboratory of Hebei Medical University for support to our experiments.

\section{Compliance with Ethical Standards}

Conflict of Interest: All authors declare no conflict of interest.

Ethical approval: All applicable international, national, and/or institutional guidelines for the care and use of animals were followed.

\section{References}


1. Bhanu Prakash, K.N., Srour, H., Velan, S.S., Chuang, K.H.: A method for the automatic segmentation of brown adipose tissue. MAGMA 29(2), 287-299 (2016). doi:10.1007/s10334-015-0517-0

2. Dinas, P.C., Nikaki, A., Jamurtas, A.Z., Prassopoulos, V., Efthymiadou, R., Koutedakis, Y., Georgoulias, P., Flouris, A.D.: Association between habitual physical activity and brown adipose tissue activity in individuals undergoing PET-CT scan. Clin Endocrinol (Oxf) 82(1), 147-154 (2015). doi:10.1111/cen. 12620

3. Virtanen, K.A., Lidell, M.E., Orava, J., Heglind, M., Westergren, R., Niemi, T., Taittonen, M., Laine, J., Savisto, N.J., Enerback, S., Nuutila, P.: Functional brown adipose tissue in healthy adults. N Engl J Med 360(15), 1518-1525 (2009). doi:10.1056/NEJMoa0808949

4. Cypess, A.M., Lehman, S., Williams, G., Tal, I., Rodman, D., Goldfine, A.B., Kuo, F.C., Palmer, E.L., Tseng, Y.H., Doria, A., Kolodny, G.M., Kahn, C.R.: Identification and importance of brown adipose tissue in adult humans. N Engl J Med 360(15), 1509-1517 (2009). doi:10.1056/NEJMoa0810780

5. Stanford, K.I., Middelbeek, R.J., Townsend, K.L., An, D., Nygaard, E.B., Hitchcox, K.M., Markan, K.R., Nakano, K., Hirshman, M.F., Tseng, Y.H., Goodyear, L.J.: Brown adipose tissue regulates glucose homeostasis and insulin sensitivity. J Clin Invest 123(1), 215-223 (2013). doi:10.1172/JCl62308

6. Berbee, J.F., Boon, M.R., Khedoe, P.P., Bartelt, A., Schlein, C., Worthmann, A., Kooijman, S., Hoeke, G., Mol, I.M., John, C., Jung, C., Vazirpanah, N., Brouwers, L.P., Gordts, P.L., Esko, J.D., Hiemstra, P.S., Havekes, L.M., Scheja, L., Heeren, J., Rensen, P.C.: Brown fat activation reduces

hypercholesterolaemia and protects from atherosclerosis development. Nat Commun 6, 6356 (2015). doi:10.1038/ncomms7356

7. Chen, Y.C., Cypess, A.M., Chen, Y.C., Palmer, M., Kolodny, G., Kahn, C.R., Kwong, K.K.: Measurement of human brown adipose tissue volume and activity using anatomic MR imaging and functional MR imaging. J Nucl Med 54(9), 1584-1587 (2013). doi:10.2967/jnumed.112.117275

8. Lota, A.S., Gatehouse, P.D., Mohiaddin, R.H.: T2 mapping and T2* imaging in heart failure. Heart Fail Rev 22(4), 431-440 (2017). doi:10.1007/s10741-017-9616-5

9. Matcuk, G.R., Jr., Jones, I.A., Mclntyre, J.A., Burt, R., Hwang, D., Cen, S., Schein, A.J., Vangsness, C.T., Jr.: Evaluation of Knee Cartilage Diurnal, Activity, and BMI-Related Variations Using Quantitative T2 Mapping MRI and Fitbit Activity Tracking. J Knee Surg (2019). doi:10.1055/s-0039-1695000

10. Wu, M., Junker, D., Branca, R.T., Karampinos, D.C.: Magnetic Resonance Imaging Techniques for Brown Adipose Tissue Detection. Front Endocrinol (Lausanne) 11, 421 (2020). doi:10.3389/fendo.2020.00421

11. Bartelt, A., Bruns, O.T., Reimer, R., Hohenberg, H., Ittrich, H., Peldschus, K., Kaul, M.G., Tromsdorf, U.I., Weller, H., Waurisch, C., Eychmuller, A., Gordts, P.L., Rinninger, F., Bruegelmann, K., Freund, B., Nielsen, P., Merkel, M., Heeren, J.: Brown adipose tissue activity controls triglyceride clearance. Nat Med 17(2), 200-205 (2011). doi:10.1038/nm.2297

12. Baba, S., Engles, J.M., Huso, D.L., Ishimori, T., Wahl, R.L.: Comparison of uptake of multiple clinical radiotracers into brown adipose tissue under cold-stimulated and nonstimulated conditions. J Nucl 
13. Nedergaard, J., Bengtsson, T., Cannon, B.: New powers of brown fat: fighting the metabolic syndrome. Cell Metab 13(3), 238-240 (2011). doi:10.1016/j.cmet.2011.02.009

14. de Las Heras, N., Klett-Mingo, M., Ballesteros, S., Martin-Fernandez, B., Escribano, O., Blanco-Rivero, J., Balfagon, G., Hribal, M.L., Benito, M., Lahera, V., Gomez-Hernandez, A.: Chronic Exercise Improves Mitochondrial Function and Insulin Sensitivity in Brown Adipose Tissue. Front Physiol 9, 1122 (2018). doi:10.3389/fphys.2018.01122

15. de Queiroz, K.B., Rodovalho, G.V., Guimaraes, J.B., de Lima, D.C., Coimbra, C.C., Evangelista, E.A., Guerra-Sa, R.: Endurance training blocks uncoupling protein 1 up-regulation in brown adipose tissue while increasing uncoupling protein 3 in the muscle tissue of rats fed with a high-sugar diet. Nutr Res 32(9), 709-717 (2012). doi:10.1016/j.nutres.2012.06.020

16. Ignacio, D.L., Fortunato, R.S., Neto, R.A., da Silva Silvestre, D.H., Nigro, M., Frankenfeld, T.G., Werneckde-Castro, J.P., Carvalho, D.P.: Blunted response of pituitary type 1 and brown adipose tissue type 2 deiodinases to swimming training in ovariectomized rats. Horm Metab Res 44(11), 797-803 (2012). doi:10.1055/s-0032-1314875

17. Stanford, K.I., Lynes, M.D., Takahashi, H., Baer, L.A., Arts, P.J., May, F.J., Lehnig, A.C., Middelbeek, R.J.W., Richard, J.J., So, K., Chen, E.Y., Gao, F., Narain, N.R., Distefano, G., Shettigar, V.K., Hirshman, M.F., Ziolo, M.T., Kiebish, M.A., Tseng, Y.H., Coen, P.M., Goodyear, L.J.: 12,13-diHOME: An ExerciseInduced Lipokine that Increases Skeletal Muscle Fatty Acid Uptake. Cell Metab 27(5), 1111-1120 e1113 (2018). doi:10.1016/j.cmet.2018.03.020

18. Wu, M.V., Bikopoulos, G., Hung, S., Ceddia, R.B.: Thermogenic capacity is antagonistically regulated in classical brown and white subcutaneous fat depots by high fat diet and endurance training in rats: impact on whole-body energy expenditure. J Biol Chem 289(49), 34129-34140 (2014). doi:10.1074/jbc.M114.591008

19. Xu, X., Ying, Z., Cai, M., Xu, Z., Li, Y., Jiang, S.Y., Tzan, K., Wang, A., Parthasarathy, S., He, G., Rajagopalan, S., Sun, Q.: Exercise ameliorates high-fat diet-induced metabolic and vascular dysfunction, and increases adipocyte progenitor cell population in brown adipose tissue. Am J Physiol Regul Integr Comp Physiol 300(5), R1115-1125 (2011). doi:10.1152/ajpregu.00806.2010

20. Cannon, B., Nedergaard, J.: Brown adipose tissue: function and physiological significance. Physiol Rev 84(1), 277-359 (2004). doi:10.1152/physrev.00015.2003

21. Khanna, A., Branca, R.T.: Detecting brown adipose tissue activity with BOLD MRI in mice. Magn Reson Med 68(4), 1285-1290 (2012). doi:10.1002/mrm.24118

22. Valente, A., Jamurtas, A.Z., Koutedakis, Y., Flouris, A.D.: Molecular pathways linking non-shivering thermogenesis and obesity: focusing on brown adipose tissue development. Biol Rev Camb Philos Soc 90(1), 77-88 (2015). doi:10.1111/brv.12099

23. Wu, J., Cohen, P., Spiegelman, B.M.: Adaptive thermogenesis in adipocytes: is beige the new brown? Genes Dev 27(3), 234-250 (2013). doi:10.1101/gad.211649.112

24. De Matteis, R., Lucertini, F., Guescini, M., Polidori, E., Zeppa, S., Stocchi, V., Cinti, S., Cuppini, R.: 
Dis 23(6), 582-590 (2013). doi:10.1016/j.numecd.2012.01.013

25. Peres Valgas da Silva, C., Hernandez-Saavedra, D., White, J.D., Stanford, K.I.: Cold and Exercise: Therapeutic Tools to Activate Brown Adipose Tissue and Combat Obesity. Biology (Basel) 8(1) (2019). doi:10.3390/biology8010009

26. Vosselman, M.J., Hoeks, J., Brans, B., Pallubinsky, H., Nascimento, E.B., van der Lans, A.A., Broeders, E.P., Mottaghy, F.M., Schrauwen, P., van Marken Lichtenbelt, W.D.: Low brown adipose tissue activity in endurance-trained compared with lean sedentary men. Int J Obes (Lond) 39(12), 1696-1702 (2015). doi:10.1038/ijo.2015.130

27. Jespersen, N.Z., Larsen, T.J., Peijs, L., Daugaard, S., Homoe, P., Loft, A., de Jong, J., Mathur, N., Cannon, B., Nedergaard, J., Pedersen, B.K., Moller, K., Scheele, C.: A classical brown adipose tissue mRNA signature partly overlaps with brite in the supraclavicular region of adult humans. Cell Metab 17(5), 798-805 (2013). doi:10.1016/j.cmet.2013.04.011

\section{Figures}

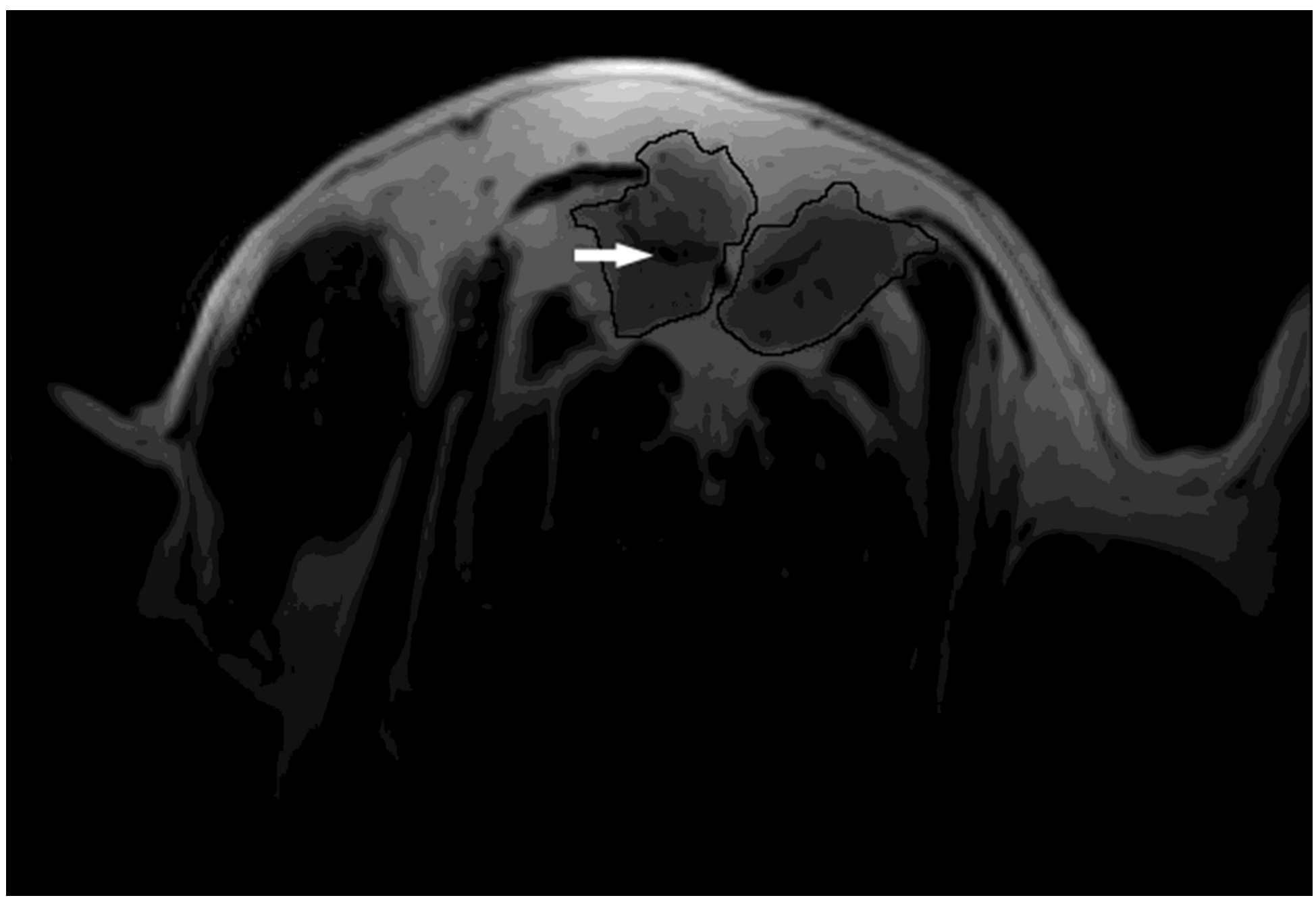

Figure 1 
A T2-weighted image (T2WI) of interscapular brown adipose tissue (BAT). The solid black line outlines BAT, which has a relatively low tissue signal compared with the surrounding area. The blood vessels within the BAT have an even lower signal (arrow), and these areas were excluded from the BAT volume measurements.

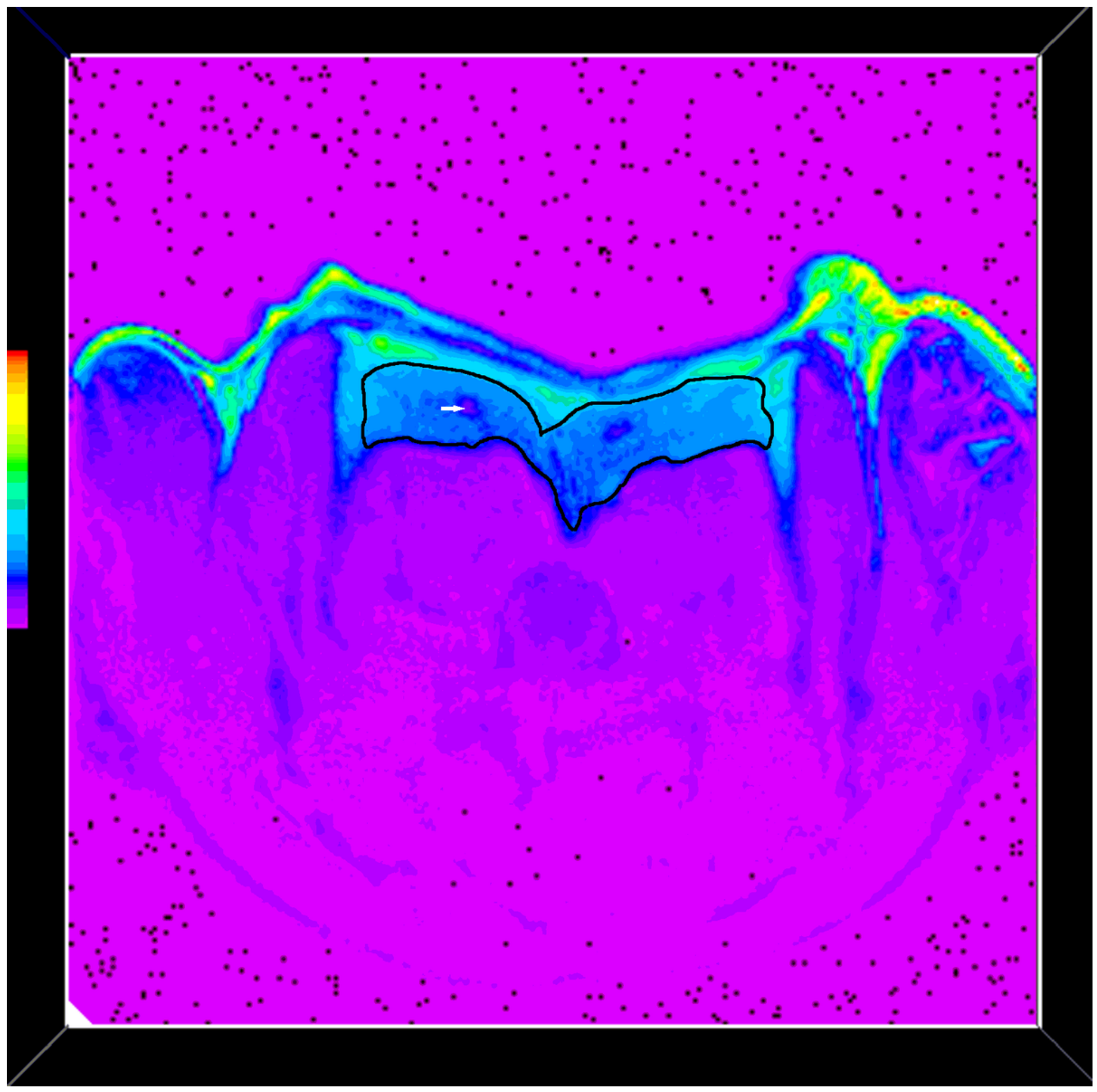

\section{Figure 2}

T2 mapping artificial color image of interscapular BAT, the solid black line outlines BAT, and we can see the blood vessels within the BAT (white arrow). Loading [MathJax]/jax/output/CommonHTML/fonts/TeX/fontdata.js 


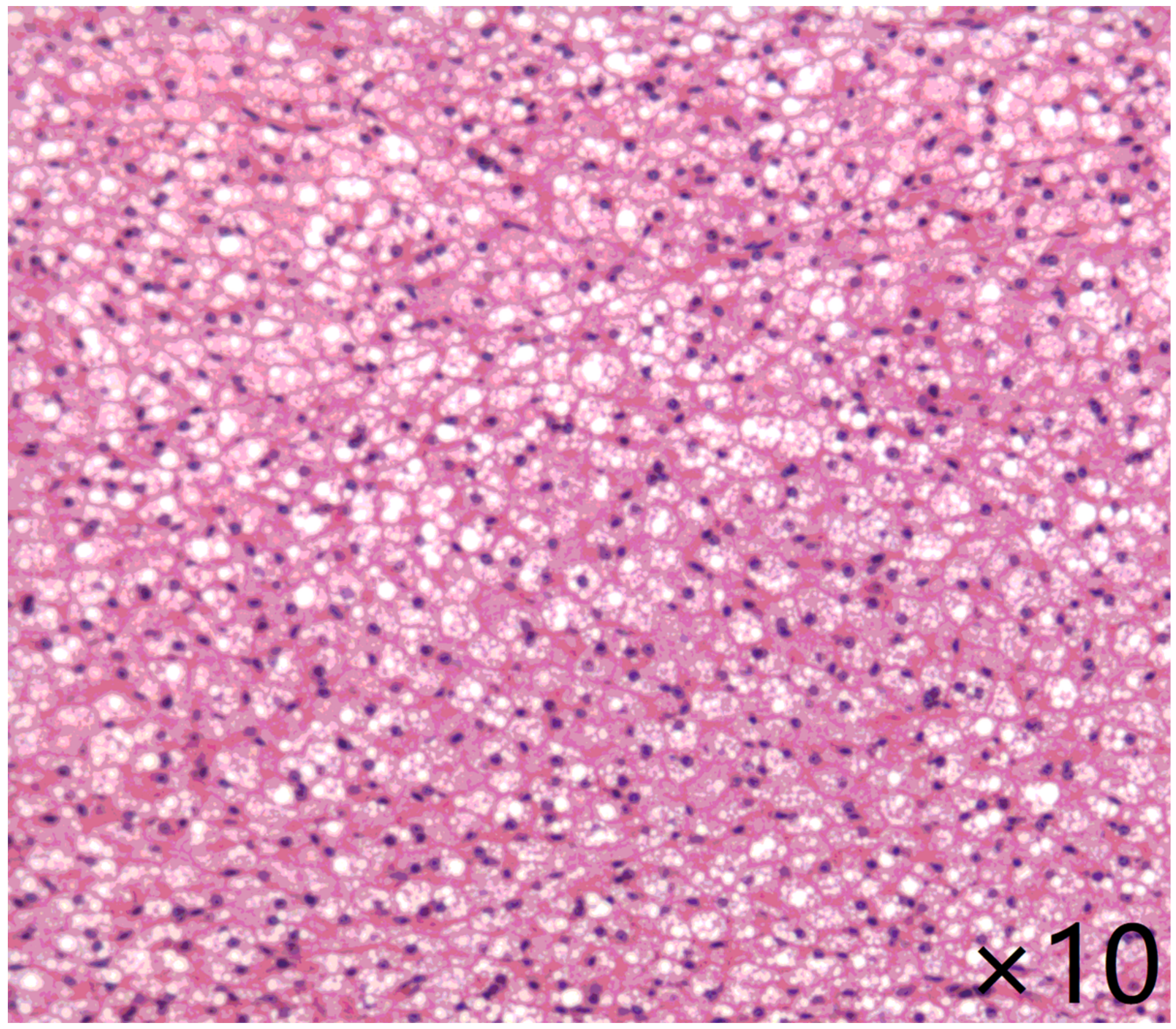

\section{Figure 3}

A photomicrograph of histopathology from the interscapular brown adipose tissue (BAT) stained with a hematoxylin and eosin stain. Multiple small lipid droplets are present, and deeply staining nuclei can be seen within the adipocytes. 


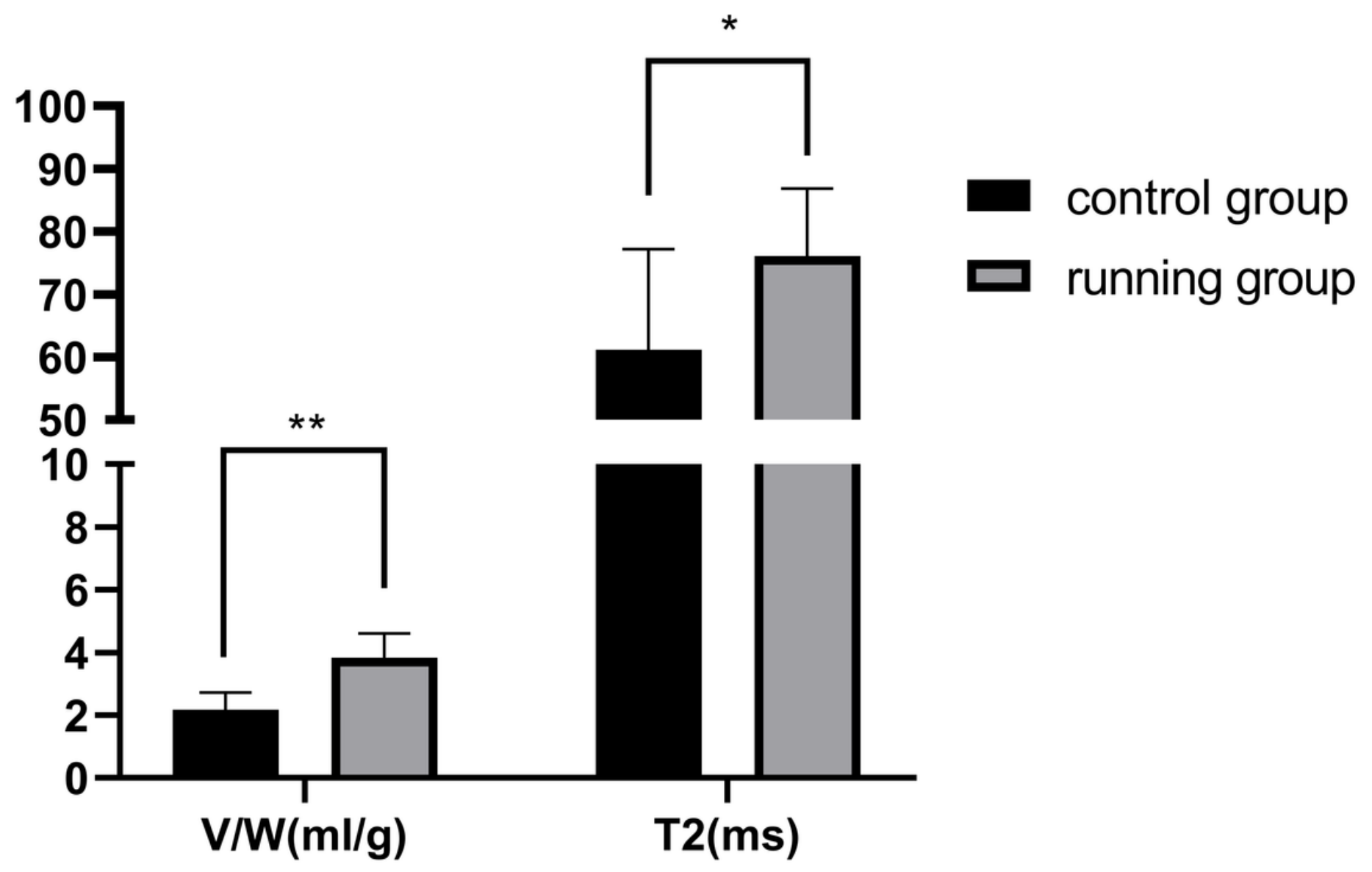

Figure 4

Bar graph showing interscapular brown adipose tissue (BAT) volume to body weight (V/W) ratios and T2 values. The BAT of the mice in the running group has higher $\mathrm{V} / \mathrm{W}$ ratios and T2 values compared with those in the control group. Values are expressed as mean \pm s.d. ${ }^{\star} P<0.05,{ }^{\star} * P<0.001$. 